Recebido: 04/03/2018

Aprovado: 01/05/2018

\title{
A Política Imigratória Brasileira na Revista de Imigração e Colonização (1940-1945)
}

Jesiane Debastiane*

Resumo: O presente artigo busca analisar a política imigratória brasileira defendida pela Revista de Imigração e Colonização durante os anos de 1940 á 1945, especificando as principais características da política imigratória do Brasil expostas nos artigos presentes neste periódico.

Palavras-chaves: Imigração; Política Imigratória; Revista de Imigração e Colonização.

Abstract: This article seeks to analyze the Brazilian immigration policy defended by the Journal of Immigration and Colonization, the official body of the Immigration, and Colonization Council during the years 1940 to 1945, specifying the main features of Brazil 's immigration policy set out in the articles in this journal.

Keywords: Immigration; Immigration Policy; Magazine of immigration and colonization.

\footnotetext{
* Mestranda em História pela UNESP, Campus Assis.
} 


\section{Introdução}

Durante o século XIX, a imigração de europeus para outros países, principalmente para o Brasil, era muito desejada. As condições econômicas e sociais favoreciam ao deslocamento de grandes contingentes de populações, conferindo, assim, a principal característica daquele período: a necessidade de emigrar e relativa liberdade de imigrar.

No Brasil, até grande parte do século XIX, ainda predominava a mão de obra escrava, principalmente na grande lavoura cafeeira, e a imigração ainda não tinha despertado interesse econômico para o Estado e para fazendeiros. Somente com a extinção do tráfico de escravos (1850) e a Lei de Ventre Livre em 1871, governo e proprietários de terras passaram a cogitar com maior ênfase a vinda de imigrantes.

O objetivo não era apenas carrear imigrantes para substituir diretamente os escravos nas lavouras ou criar núcleos de povoamento com funções especificas de ocupação e defesa. Havia um propósito mais ambicioso de superação do trabalho compulsório e, consequentemente, de formação de uma nova sociedade espelhada nos padrões europeus, na qual a contribuição dos imigrantes seria fundamental (GONÇALVES, 2008: 127).

Em meados de Oitocentos, uma experiência desenvolvida pela iniciativa particular de Nicolau Campos Vergueiro, promoveu a imigração, sob o sistema de parceria. Com o fim do sistema escravista, o governo como também cafeicultores que se viram sem mão de obra, intensificaram novas experiências de trabalho com a mão de obra imigrante.

No sistema de parceria, os imigrantes em grupos familiares eram contratados na Europa e trazidos para as fazendas de café, principalmente para o interior de São Paulo. A viagem e o transporte eram financiados pelo próprio fazendeiro. O sistema de parceira foi substituído pela locação de serviços, não obtendo grandes resultados. No final do século XIX ganhou forma o regime de trabalho denominado de colonato.

Na década de 1880, surgiu a Imigração Subvencionada, caracterizada pelo financiamento das passagens pelo governo, o que desonerava imigrante e fazendeiro dessa significativa despesa. Foram organizadas na Europa campanhas de propaganda com o intuito de trazerem para o Brasil os imigrantes que se propusessem a trabalhar nas fazendas de café. 
O sistema de imigração subvencionada permaneceu até o fim da década de 1920. $\mathrm{Na}$ década de 30 teve inicio um novo debate sobre imigração que resultou em um maior controle da imigração, sendo esta mais restritiva e seletiva, tendo como base as ideias eugênicas que predominaram durante o Governo Vargas.

\begin{abstract}
A política de estrangeiros do primeiro período da Era Vargas assumiu expresso caráter seletivo, com base em critério étnico, muito além da premissa de proteger o trabalhador nacional, alegação presente nas normas restricionistas editadas entre 1930 e 1933 (MENDES, 2013: 461).
\end{abstract}

No Brasil as ideias eugênicas ganharam destaque nos meios intelectuais e políticos do Governo Vargas, em um país que apresentava uma grande miscigenação, as ideias eugênicas surgiram como uma forma de construção de um projeto nacional, através destas ideias se pretendia realizar um projeto de branqueamento da população brasileira visto como forma de atraso e de degeneração. O projeto de branqueamento da população brasileira consistia em trazer para o país imigrantes europeus brancos com o intuito de melhorar a população brasileira.

A eugenia se tornou muito presente no que tange a imigração, através de ideias eugênicas os imigrantes passaram a serem selecionados de acordo com seus aspectos físicos, mentais, ao mesmo tempo em que determinadas nacionalidades passaram a serem vistas como adequadas ou não para a formação do povo brasileiro.

Pode-se perceber a influência das ideias eugênicas na Assembleia Nacional Constituinte de 1933-1934, onde diversos políticos apresentaram propostas sobre a política imigratória, impedindo ou restringindo a vinda de imigrantes asiáticos e negros, e incentivando a vinda de europeus brancos.

O resultado desse intenso debate ocorrido na Assembleia Constituinte foi à adoção da Lei de Cotas de $2 \%$, que estabelecia "o limite anual de dois por cento para cada nacionalidade, referente ao número total dos respectivos imigrantes fixados no Brasil nos últimos cinquenta anos (REVORÊDO, 1934: 47).

Desta forma, houve uma diminuição no número de entradas de imigrantes no país, sendo que os japoneses foram a nacionalidade que mais tiveram seus números reduzidos.

Um dos principais impactos da Lei de Cotas foi exatamente o grande aquecimento do debate público sobre a imigração e sobre a incorporação das populações de origem estrangeira, e,

\title{
Filstortorias
}


consequentemente, uma ampla divulgação dos discursos eugenistas e dos temores em relação aos imigrantes, os japoneses inclusive (GERALDO, 2009:206).

Após o regulamento da "lei de cotas", foi aprovado em 09 de Maio de 1934 o Decreto n.24.215 regulamentado pelo decreto n.24.258, que dispõe sobre a entrada de estrangeiros em território nacional.

O Decreto n.24.215 dispõe sobre a entrada de estrangeiros em território nacional, desta forma, enumerando os imigrantes que não seriam aceitos em território nacional: aleijado, mutilado, cego, surdo-mudo, deficiente mental, deficiente físico, toxicômano, menor de dezoito anos e maior de sessenta anos, cigano, nômade, que não apresentassem profissão lícita, analfabetos, de conduta manifestante a ordem publica, estrangeiros que em algum momento foram expulsos do Brasil.

Logo que se inicia o Estado Novo sob o comando de Getúlio Vargas, foi instaurado no Brasil o Decreto-Lei n. 406 de 04 de Maio de 1938, este Decreto dispunha sobre a entrada de estrangeiros no país e criava o Conselho de Imigração e Colonização (CIC), órgão responsável pela Revista de Imigração e Colonização (RIC).

\section{A Revista de Imigração e Colonização}

Com o Decreto-Lei n.406 criou-se o Conselho de Imigração e Colonização (CIC), órgão relacionado diretamente ao presidente do Brasil, Getúlio Vargas, que tinha como funções fixar as cotas de acordo com os dados fornecidos pelo Ministério das Relações Exteriores e pelo Departamento de Imigração, propor medidas que favorecessem a assimilação e nacionalização dos imigrantes, evitar a concentração de imigrantes em qualquer ponto territorial do país, estudar as melhores correntes imigratórias ao país.

O Conselho era composto por um Presidente, dois Vice-Presidentes, quatro Conselheiros, além dos Observados do Estado, todos sendo homens ligados à elite do Governo Vargas. Posteriormente ao surgimento do Conselho, em 1940 foi publicada a primeira edição da Revista de Imigração e Colonização (RIC).

Neste artigo foram utilizadas as edições de 1940 a 1945, totalizando o número de dezoito edições. Analisando brevemente a estrutura da Revista, vemos que sua principal função era divulgar assuntos relacionados à imigração, colonização, povoamento, artigos tratando de várias temáticas sobre a imigração, legislação, decretos, estatísticas, 
noticiário, enfim vários assuntos que se enquadravam na atual política imigratória no Brasil do período.

Eram publicadas na maioria das vezes quatro edições por ano e em alguns casos contemplava dois números na mesma edição. A revista apresentava em seu sumário uma parte destinada aos Artigos, a Legislação, Estatísticas, Noticiário e Livros e Revistas. Na primeira edição de cada, o Conselho realizava um balanço ou relatório de suas atividades no ano anterior, são extremamente interessantes estes relatórios, pois através destes temos uma breve ideia do funcionamento do Conselho em termos burocráticos e também das atividades empenhadas por este órgão.

Ao analisar a Revista percebemos que a parte mais volumosa do periódico e onde se encontram a visão dos membros do Conselho e de seus colaboradores são os Artigos, e são através destes que pretendo demonstrar como a Revista se tornou um porta-voz da politica imigratória do período.

Os pensadores da Revista eram convidados pelo Conselho de Imigração e Colonização (CIC) a publicarem seus artigos no periódico, eram todos homens relacionados a questões de terra, povoamento, colonização, imigração, demografia, ou seja, a elite intelectual do Estado Novo.

Como a Revista era escrita pela elite do Governo Vargas, ou seja, homens que concordavam com a política imposta pelo Governo, a Revista defendia através de seu conteúdo uma política imigratória restritiva e seletiva, apontando quais correntes imigratórias eram desejáveis para o processo de branqueamento da população brasileira e quais eram indesejáveis ao país.

Durante o Estado Novo a política imigratória buscou restringir os imigrantes indesejáveis e selecionar o imigrante mais adequado ao país e ao processo de branqueamento da população brasileira, que era o europeu branco, deixando claro que havia um controle das correntes imigratórias que entravam no Brasil.

$\mathrm{Na}$ Revista encontramos diversas vezes o discurso sobre a imigração controlada, de acordo com João Carlos Muniz, presidente do Conselho de Imigração e Colonização (CIC);

A intervenção do Estado é cada vez mais decisiva nos movimentos migratórios, planificando, selecionando e dirigindo as correntes humanas, de acordo com os interesses dos países de emigração e imigração. Dai a necessidade de uma maior organização e centralização

\section{Filstontorias}


em matéria de imigração em geral e, principalmente, em se tratando de imigração colonizadora (MUNIZ, 1940: 03).

Entre as características da política imigratória do Estado Novo estava a necessidade de colonização e povoamento do Brasil. Países como o Brasil necessitaria de grandes contingentes imigratórios para a colonização e povoamento, pois apresentavam uma baixa densidade demográfica nas áreas do interior, desta forma, aumentando o contingente imigratório, aumentaria seu desenvolvimento demográfico e consequentemente econômico. Estes imigrantes seriam deslocados para o interior do país com o intuito de trabalharem na agricultura.

Com a vinda de imigrantes para o país, o Governo deveria incentivar a assimilação e nacionalização do imigrante, o próprio Getúlio Vargas apresenta esta questão na Revista:

\footnotetext{
Entre as medidas de efeito imediato, a mais relevante refere-se a obra de nacionalização iniciada nas escolas, em algumas regiões onde o afluxo da colonização estrangeira poderia criar, no curso do tempo, centros estranhos as pulsações da vida brasileira, pela persistência de costumes, hábitos, tradições e modos de ser peculiares a outras raças. A língua é um nobre instrumento de afirmação da soberania nacional...As forças armadas, que são instituições modelarmente nacionais e, portanto, forças nacionalizadoras, estão empenhadas nessa bela obra de patriotismo e, também de previdência (NEIVA, 1942: 51).
}

O governo impedia através de constantes fiscalizações a difusão dos costumes e culturas de outras nacionalidades, é comum encontrar na Revista a preocupação do Conselho e do Governo com a nacionalização desses imigrantes, para isso eram adotadas algumas medidas como: construções de escolas nos meios rurais reforçando a língua portuguesa e proibindo a língua pátria destes imigrantes, desta forma, reforçando o estrangeiro em se adequar a língua brasileira, também havia a imposição dos costumes brasileiros como o folclore nos núcleos coloniais.

Fazia parte da política imigratória do Governo a imigração interna, era muito recorrente a vinda de nordestinos para São Paulo, desta forma, como parte das tarefas do Conselho de Imigração e Colonização era conter a migração de nordestinos, para isso eram realizadas frequentes visitas ao Nordeste buscando meios para fixá-los em suas terras. O nordeste naquele período era uma região onde ocorriam intensas secas, o que

\section{Filstontorias}


acarretava a saída de nordestinos para o Sudeste do país e também, durante o período analisado, para a Amazônia.

A Revista de Imigração e Colonização dedicou três edições de seu periódico para debater a questão de migração de nordestinos e a seca, através de relatórios e artigos de seus membros vemos a preocupação do Governo com estes temas.

O problema da seca sempre persistiu no Nordeste, uma maior preocupação com esta questão só ocorreu a partir do Governo Provisório, até 1930, as relações entre os governantes e os retirantes haviam se baseado num terreno movediço mal delimitado, de um lado, pelos costumes tradicionais da vida sertaneja e, de outro, pelo "liberalismo oligárquico" que dominava a esfera do Estado no Brasil, com todas as suas peculiaridades. As demandas apresentadas pelos refugiados da seca, nesse contexto, eram recebidas pelas autoridades ora com desdém - confiantes na capacidade do mercado de reequilibrarse por si mesmo e na secular submissão do homem do campo -, ora com temor - diante das possibilidades de revolta contidas na formação da multidão como agente de organização popular (NEVES, 2001: 113).

Uma das principais características da política imigratória brasileira era a seleção e restrição dos imigrantes. O imigrante estrangeiro durante o Governo Vargas passou a ser analisado como desejável e indesejável e, com isso, tornou cada vez mais complicada a entrada de estrangeiros no decorrer da Segunda Guerra Mundial.

Entre os imigrantes desejáveis estavam os de origem europeia de cor branca, podemos destacar nesta categoria os portugueses. Os portugueses eram aceitos pelo governo de Getúlio Vargas, por serem considerados como a "matriz" do povo brasileiro, por apresentarem maior facilidade de assimilação étnica.

Muitos portugueses que vieram para o Brasil, diferentemente do que estipulava a política imigratória, de que os imigrantes deveriam ir para o interior, principalmente para o meio rural, foram para os centros urbanos. Durante todo o governo de Vargas, muitos decretos-leis restringiram a imigração estrangeira, entretanto estes não eram aplicados aos portugueses.

Um exemplo disso foi a Lei de Cotas que estava presente no Decreto-Lei n.406, nesta estava decretado que os portugueses estavam isentos das cotas:

O Conselho de Imigração e Colonização, pela resolução n.34 de 22 de Abril de 1939 resolveu considerar os portugueses para os efeitos do

\section{Filstontorias}


Decreto n.3.010 de 20 de Agosto de 1938, isentos de qualquer restrição numérica quanto a sua entrada no território nacional ${ }^{1}$.

Enquanto as demais nacionalidades sofriam reduções em seus números de entradas, até mesmo italianos e espanhóis, os portugueses não encontravam nenhum empecilho para entrar no país.

\begin{abstract}
Nesse quadro de imposição de limites à entrada de imigrantes, a política estado- novista estabeleceu uma situação peculiar para os portugueses, habilitando privilégios que os distinguiram em dois sentidos: 1) os portugueses foram deixados de fora da legislação brasileira restritiva à admissão de novos imigrantes, ao mesmo tempo em que 2) se procurou incrementar a sua imigração, por todos os motivos a mais aconselhável para o Brasil, nas palavras do presidente do Conselho de Imigração e Colonização, Frederico de Castello Branco Clark, direcionadas ao ministro das Relações Exteriores Oswaldo Aranha (MENDES, 2010: 256)..
\end{abstract}

Na Revista de Imigração e Colonização referente aos relatórios do Conselho eram frequentemente debatidos meios para facilitar e promover a vinda de imigrantes portugueses para o Brasil. "A imigração portuguesa convinha perfeitamente ao ambiente brasileiro e à progressiva nacionalização do país, visto que ela servia para preservar a sua constituição étnica e seus interesses econômicos"2.

Ao mesmo tempo em que a Revista defendia a imigração de determinadas nacionalidade, o periódico também restringia a entrada de determinados estrangeiros, conforme o Decreto-Lei n. 406 que restringia a entrada de estrangeiros em território nacional, entre os estrangeiros que eram impedidos de virem para o Brasil estavam: pessoas com deficiência física e mental, menores de 18 anos e maiores de 60 anos, pessoas de conduta que fossem contra os ideais do Governo.

Embora não fosse expressa de forma clara na Legislação, entre o grupo de indesejáveis também estavam às nacionalidades vistas como "amarelas", no caso os asiáticos, principalmente os japoneses, e os negros e os judeus.

Antropólogos, psiquiatras, militares, juristas, médicos, eugenistas, economistas, jornalistas e escritores dedicaram-se a pensar essa questão, procurando detectar os responsáveis pelos males que

\footnotetext{
${ }^{1}$ Decreto-Lei n.406, de 04 de maio de 1938 In Revista de Imigração e Colonização. Rio de Janeiro. Ano I, N.1. Janeiro de 1940. p.72.

${ }^{2}$ Este discurso encontra-se presente no Primeiro ano de trabalhos do Conselho de Imigração e Colonização In Revista de Imigração e Colonização. Rio de Janeiro. Ano I. N.1. Janeiro de 1940. p.14.
} 
assolavam o país. Apropriando-se dos modelos oferecidos pelos teóricos racialistas europeus e valorizando os métodos sugeridos pela Eugenia, Antropologia Social e Antropologia Criminal, essa elite intelectual ditou regras para a "higienização" da sociedade. Mascarados por uma retórica nacionalista, classificavam os negros, os judeus, os japoneses e os árabes como "raças indesejáveis" para compor a população brasileira (CARNEIRO, 2003: 06).

A restrição aos imigrantes negros já havia sido debatida na Assembleia Constituinte, diversas propostas feitas pelos membros da Assembleia alegavam que a imigração de negros não era interessante para o país. Estrangeiros negros não eram bemvindos ao país, porque interfeririam no processo de branqueamento da população brasileira, no Brasil naquele período já existiam um grande número de negros, mulatos. Uma das ideias presentes na época era a de que os negros eram os responsáveis pelo atraso do país, desta forma, trazendo imigrantes europeus brancos ocorreria um branqueamento da população e posteriormente, o Brasil sairia de atraso em que se encontrava.

Os imigrantes japoneses foram um dos grandes alvos das politica imigratória do Governo Vargas, foram amplamente criticados na Revista de Imigração e Colonização (RIC). Em diversos artigos estes imigrantes são vistos como inassimiláveis.

A esse respeito alemães, poloneses e outros europeus não devem ser considerados no mesmo plano dos japoneses. Ainda que trazendo ao Brasil cultura, língua e costumes diferentes da cultura, língua e dos costumes brasileiros, força é reconhecer que os primeiros são etnias cuja interação biológica na coletividade nacional só poderá favorecernos (COUTO, 1941:21)

Isso demonstra que a imigração de japoneses ao Brasil não traria bons resultados a população brasileira. Alguns dos intelectuais do Governo Vargas viam a imigração japonesa como uma forma de ação militar, fazendo do Brasil uma base militar contra os Estados Unidos e toda a América Latina.

E um novo sistema de imigração surgiu, assim para a terra: a imigração de conquista, militarmente, organizada, visando a formação de minorias raciais em ultramar, como assim fez principalmente o Japão na Ásia Continental, em ilhas do Pacífico, em quase toda a América e, muitos especialmente, no Brasil...Eles aqui continuam, perfeita e completamente, organizados, armados, até de dinamite e prontos para executar a traição, qualquer ação bélica contra nós e nossos aliados, no dia, na hora e no instante mesmo em que, neste sentido, receberem ordem de Tóquio (OLIVEIRA, 1944:643).

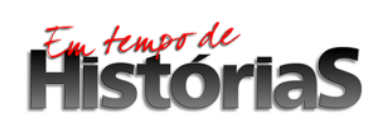

(PPGHIS/UnB) №. 32, Brasília, Jan - Jul 2018 ISSN 2316-1191 
Em um artigo da Revista é agradecido aos três heróis da campanha antinipônico, Félix Pacheco, Arthur Neiva e Miguel Couto por apresentarem medidas contra a entrada de japoneses durante a Assembleia Constituinte, neste artigo podemos perceber a imagem negativa que se faz ao japonês, além de serem considerados alienígenas, eram terroristas que viriam conquistar uma parte do Brasil para seu império.

É interessante notar que embora seja sempre mencionado na Revista o japonês como inassimilável, em um relatório de viagem feita as áreas de colonização japonesa no Estado de São Paulo, relata que a imigração japonesa foi essencialmente uma imigração agrícola, ou seja, $80 \%$ se dirigiam ao interior do país para trabalharem na terra, além disso, ressaltam a admirável organização que apresentam os japoneses nessas colônias.

Os judeus foram outro grupo que sofreram grandes restrições durante o Governo Vargas, mas precisamente a partir do inicio da Segunda Guerra Mundial. Os judeus como os demais grupos considerados indesejáveis, eram vistos como inassimiláveis, taxados como extremamente comerciantes, desta forma, não iriam para o interior do país trabalharem na agricultura e em muitos casos eram considerados de esquerda, como uma ameaça comunista.

A Revista de Imigração e Colonização (RIC) traz em seus artigos algumas analises acerca destes estrangeiros, sempre mencionado no periódico que não havia nenhum tipo de preconceito contra os judeus, porém sua entrada era restrita.

Segundo Dr. Castro Barreto entre os imigrantes que recebemos neste ultimo quinquênio predominou a etnia judaica. $\mathrm{O}$ afluxo de judeus nas nossas grandes cidades é tão patente que surpreende a todos os observadores a sua invasão crescente no mundo dos adquirentes de imóveis, dos comerciantes e dos universitários... Não nos move qualquer preconceito contra os judeus; estamos, porém de acordo com o ilustre médico patrício quanto a inconveniência de se alargar a sua admissão na comunidade brasileira, em virtude da intolerância sectária, principal causa do seu baixo coeficiente de assimilação (CARVALHO, 1943: 75-76).

No periódico Oliveira Vianna em seu artigo “Os imigrantes semíticos e mongóis e suas caracterização antropológica" se mostra contra a entrada de judeus no país, pois para ele esse grupo não era assimilável.

Um artigo da revista especificamente sobre os judeus merece destaque, escrito por Arthur Hehl Neiva, um dos membros do Conselho de Imigração e Colonização (CIC) 
entre os anos de 1938 a 1947, neste artigo o autor tece várias ideias acerca da imigração judaica. Para o autor, diferentemente de muitos intelectuais do Governo Vargas, Arthur não via motivos que impedissem a vinda de judeus para o Brasil:

Utilizemo-nos deles (judeus) como um dos ingredientes do nosso melting-pot, como já o fizemos em séculos passados. Politicamente, não nos podem ser prejudiciais; economicamente, só nos trarão vantagens; socialmente, assimilam-se sem dificuldades; etnicamente, são brancos; não devemos ter preconceitos religiosos, em pleno século XX e mesmo pela doutrina católica, não nos é licito discriminar (NEIVA, 1944: 258).

Para autores da Revista de Imigração e Colonização (RIC) um dos motivos para a restrição dos judeus seria o fato de serem exclusivamente comerciantes, entretanto, Arthur Hehl Neiva acreditava que embora eles, em sua grande maioria, se dedicassem ao comércio, indústria, artesanato, crédito, quando obrigados a trabalharem no meio agrícola, se dedicariam obtendo sucesso.

Segundo o autor os judeus que vieram para o Brasil seriam divididos em dois grupos os Sefardim e os Askenazim. Os judeus Sefardim vieram da Península Ibérica, considerados judeus ocidentais e os judeus Askenazim eram alemães e polacos, considerados judeus orientais. A maioria dos judeus que se estabeleceram no país seriam os judeus ocidentais, e eram estes judeus que seriam mais adequados a politica imigratória do país.

O autor acredita que o país poderia receber ao todo 2.500 judeus por ano, sendo 750 do grupo de judeus orientais. "A entrada de judeus ficaria sujeita, tal como a de quais quer outros imigrantes, as restrições constitucionais da cota, impostas em virtude das nacionalidades, e não da raça, ou da origem" (NEIVA, 1944:393).

Outro detalhe que o autor esclarece era acerca do antissemitismo que possa haver no país, segundo o autor "não há sentimento antissemita no país e não se deve importalo. Nunca fomos antissemitas, nunca fizemos distinção de raça, cor ou religião" (NEIVA, 1944:401).

Embora Arthur Hehl Neiva demonstre que não havia preconceitos de raça, cor, a autora Maria Luiza Tucci Carneiro acredita que:

Desde a instauração do Estado Novo, em novembro de 1937, o governo brasileiro procurou impedir a imigração dos judeus refugiados do

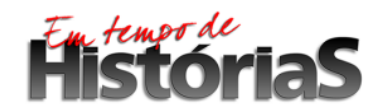

(PPGHIS/UnB) №. 32, Brasília, Jan - Jul 2018 ISSN 2316-1191 
nazismo e dos sobreviventes dos campos de concentração. Indiferentes ao drama vivenciado pelos judeus na Europa, as autoridades brasileiras optaram pela adoção de uma política imigratória seletiva e restritiva. Valendo-se de velhos argumentos antissemitas, interpretaram essa imigração como uma ameaça à integridade étnica e religiosa da população, idealizada como branca e católica (CARNEIRO, 2007: 02).

O que podemos perceber pelos artigos da Revista de Imigração e Colonização (RIC) é que a politica de imigração relacionada aos judeus era contraditória, ao mesmo momento que intelectuais da época admitiam os judeus como inassimiláveis, outros membros da elite os viam como uma corrente imigratória interessante ao país, desde que devidamente selecionada, priorizando a imigração de brancos europeus, e embora a Segunda Guerra Mundial tenha dificultado a vinda de judeus, eles continuaram entrando no país.

Sobre a politica imigratória imposta aos judeus, Jeffrey Lesser afirma que:

O resultado é que as posições sobre a imigração judaica estavam em constante mutação. Os judeus eram considerados não-brancos e incompatíveis com a política de branqueamento racial do Brasil e, simultaneamente, vitais para o desenvolvimento econômico do país (LESSER, 1995: 307).

Em relação ao sentimento de antissemitismo, houve no país restrições aos judeus, enquanto os números destes imigrantes eram de 2.500 por ano, os japoneses, vistos como uma nacionalidade inassimilável, inadequada ao país, apresentava a cota de 2.849 por ano, ou seja, houve restrições aos judeus, houve um sentimento antissemita, mas não práticas antissemitas, como houve com o nazismo na Europa.

Marcos Chor Maio ao analisar o antissemitismo no Brasil, acredita que:

Nessa perspectiva relacional, pode-se entender, além dos cálculos utilitários de Getúlio Vargas em face dos judeus em suas conexões externas, condicionantes internos relativos ao modo como segmentos da elite política pregavam máximas antissemitas que não se traduziam, em diversos momentos, em práticas antissemitas (MAIO, 1999: 249).

Em geral, a Revista defendia a politica imigratória mais adequada ao país, enfatizando em seus artigos as correntes imigratórias que eram indesejáveis para o processo de branqueamento da população, ao mesmo tempo em que deixava clara a sua preferencia por imigrantes brancos e agricultores.

\section{Hitstorias}




\section{A Revista de Imigração e Colonização (RIC) e seus críticos}

A Revista apresenta poucos trabalhos que se debruçam a realizar uma análise mais crítica em torno deste periódico, entretanto alguns autores acabam por citá-la de forma rápida, desta forma, realizando algumas críticas referentes ao seu conteúdo e linguagem empregada.

Como já sabemos a Revista é um periódico que defendia e difundia a política imigratória adequada ao país, de acordo com os ideais do Estado Novo, enfatizando em seus artigos as melhores nacionalidades que pudessem contribuir com o processo de branqueamento e progresso da população brasileira, ao mesmo tempo apontava as etnias que não eram adequadas ao país.

Elena Pájaro Peres ao realizar um trabalho a cerca do discurso da Revista, "a considera como um porta-voz de um pensamento racista, legitimador da política discriminatória do governo Vargas em relação ao estrangeiro” (PERES, 1997:86).

Erica Sarmiento da Silva considera que Getúlio Vargas utiliza os meios de comunicação a favor do Estado para publicar o perfil do imigrante desejável à contribuição do desenvolvimento do país.

Um exemplo é a Revista de Colonização e Imigração, nas décadas de 30, 40 e 50, onde vários intelectuais divulgam suas ideias xenófobas acerca de determinados grupos de imigrantes. O conteúdo da revista centrava-se em assuntos diretamente relacionados à imigração, reproduzindo artigos publicados pela grande imprensa. Durante o Estado Novo, ela foi porta-voz de um pensamento racista, legitimador da política discriminatória do governo Vargas em relação ao estrangeiro (SILVA, 2007: 144).

Giralda Seyferth aponta o caráter dos textos publicados pela Revista de Imigração e Colonização:

Os diferentes autores que postulavam políticas imigratórias não só procuraram estabelecer critérios para selecionar imigrantes adequados aos interesses nacionais, como demonstravam seus receios nativistas diante da situação étnica produzida pelos diferentes grupos já estabelecidos no país, resultando disso uma ênfase na unidade nacional, na ocupação do território e nas possibilidades de assimilação (SEYFERTH,1999: 214).

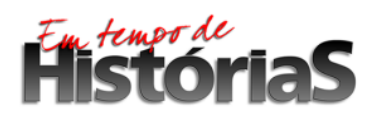

(PPGHIS/UnB) №. 32, Brasília, Jan - Jul 2018 ISSN 2316-1191 
Maria Luiza Tucci Carneiro, uma grande critica da política imigratória de Vargas, menciona que:

Através de artigos 'cientificamente' redigidos e assinados por autoridades médicas, diplomáticas, bacharéis em direito, sociólogos e educadores, a revista defendeu nos anos de 1940 a manutenção de uma política imigratória restritiva apoiada em critérios étnicos, políticos e morais (CARNEIRO,1995:184).

Camila Almeida Belarmino acredita que o discurso da Revista de Imigração e Colonização caracteriza o desenvolvimento de medidas imigratórias com caráter evolutivo em busca do atendimento das necessidades do Brasil.

E continua nas páginas da Revista de Imigração e Colonização, é possível encontrar não somente questões ou problemáticas relativas ao Brasil, mas também, como muito utilizado pela propaganda Estado Novista, a exaltação da pátria a partir de suas riquezas: "Brasil magnífico, Brasil gigante adormecido da América do Sul, Brasil, país de grande futuro, Brasil nação em formação." Ainda sim, nesta declaração ufanista, podemos observar a perspectiva que ao Estado Novo cabe a responsabilidade de constituir a nação, uma nação que está em processo de formação, que é rica, e até o momento não soube aproveitar disso (BELARMINO, 2012: 123).

Através das críticas citadas pelos autores acima, percebemos que são unanimes em considerar a Revista de Imigração e Colonização (RIC) como um periódico racista, seletivo, que desumanizava o imigrante o tratando apenas como um objeto, sendo facilmente descartado.

Isto se deve ao fato de que o periódico apresentava uma linguagem preconceituosa, que empregava termos como "inassimiláveis, alienígenas, suicidas, traiçoeiros" para identificar determinados imigrantes, principalmente os japoneses. Outro fato é que, como já foi comentado, a Revista era o porta-voz da politica imigratória do Governo Vargas, representava a visão da grande maioria dos intelectuais da época.

\section{Considerações Finais}

A Revista de Imigração e Colonização (RIC) é uma fonte muito rica para se compreender a política imigratória defendida durante os anos de 1940-1945 e os anos seguintes, como um periódico criado pelo um órgão relacionado diretamente ao 
Presidente da República, ela transfere aos seus leitores as principais ideias acerca de uma política imigratória adequada ao país, desta forma, tendo como pano de fundo a defesa do trabalhador nacional em relação ao estrangeiro.

$\mathrm{Na}$ Revista o que mais chama a atenção dos leitores são os artigos, suas temáticas todas relacionadas à imigração e colonização, refletem as ideias do governo e elite, demonstram a preocupação na seleção da melhor nacionalidade ao país, abordando aspectos físicos, biológicos e culturais destas nacionalidades. Devido a isto acredito que a Revista de Imigração e Colonização (RIC) era um porta-voz da política imigratória imposta por Getúlio Vargas e retratava a mesma linguagem, a mesma preocupação que a elite do Estado Novo possuía em relação aos imigrantes.

Havia uma seleção dos imigrantes desejáveis e indesejáveis, como percebemos os portugueses eram aceitos no país sem nenhuma restrição, além de estarem isentos do sistema de cotas de entrada. Diferentemente para os japoneses e judeus, os imigrantes japoneses desde a Assembleia Constituinte sofriam restrições em sua entrada, além de serem vistos como inassimiláveis e a eles relacionado à ideia de que construiriam no Brasil uma extensão do império japonês.

No caso dos judeus vemos claramente as restrições impostas a eles, tanto no sistema de cotas como na imagem de serem inassimiláveis, inferiores.

A imigração de judeus aparece como algo contraditório durante o Governo Vargas, pois temos intelectuais ligados ao Governo sendo contra a vinda destes estrangeiros, por outro lado, um artigo de Arthur Hehl Neiva indica que não havia preconceito contra os judeus, apenas restrições como as demais nacionalidades, preferindo os judeus considerados ocidentais, porém o numero de entrada imposto pelo Conselho a estes estrangeiros é inferior até mesmo em relação aos japoneses.

Concluindo a Revista de Imigração e Colonização (RIC) foi muitas vezes vista como um periódico racista e preconceituoso, além de ser um guia da politica imigratória brasileira ao longo dos anos de 1940 a 1955, trazendo aos seus leitores o debate imigratório presente no período.

Através dos artigos, vemos claramente a posição da elite intelectual acerca da imigração mais adequada ao país, que preferiria imigrantes brancos europeus devidamente selecionados, ao mesmo tempo em que restringia os estrangeiros negros, asiáticos, judeus, deixando claro que se iniciava um novo período na historia da imigração 
brasileira, marcado por um processo de restrição e seleção dos estrangeiros e pela busca do branqueamento da população e o progresso do país.

\section{Referências Bibliográficas}

\section{Fonte Primária}

Revista de Imigração e Colonização. Órgão Oficial do Conselho de Imigração e Colonização. Rio de Janeiro. Referente aos anos de 1940 a 1945.

\section{Fontes Secundárias}

BELARMINO, Camila Almeida. Diálogos para construir uma nação: continuidades da questão nacional do pensamento social brasileiro nas páginas da Revista de Imigração e Colonização. 2012. $140 \mathrm{f}$. Dissertação (Mestrado em História). Programa de Pós-Graduação e História das Instituições da Universidade do Estado do Rio de Janeiro. 2012.

CARNEIRO, Maria Luiza Tucci. "A imagem do imigrante indesejável. Arquivo Público do Estado e Universidade de São Paulo". Seminários - $n^{\circ}$ 3: Crime, Criminalidade e Repressão no Brasil República. São Paulo.

CARNEIRO, Maria Luiza Tucci. Muralha anti-semita. Inspiradas em ideias racistas, autoridades do Estado Novo impediram a entrada de refugiados judeus no Brasil. Revista de História. Novembro de 2007.

CARNEIRO, Maria Luiza Tucci. O anti-semitismo na era Vargas (1930-1945), São Paulo. ed. Brasiliense, 1995.

CARVALHO, Fernando Mibielli de. Ainda a imigração do Após-Guerra. Revista de Imigração e Colonização. Rio de Janeiro. Ano IV, N.4. p.67-80.1943

COUTO, R. Ribeiro. O problema da nacionalização. Revista de Imigração e Colonização. Rio de Janeiro. Ano II, n.1. p.18-34.1941.

GERALDO, Endrica. A "lei de cotas" de 1934: controle de estrangeiros no Brasil. Campinas. Cad. AEL, v.15, n.27. 2009.

GONÇALVES, Paulo Cesar. Mercadores de Braços, Riqueza e Acumulação na Organização da Emigração Europeia para o Novo Mundo. 2008. 518 f. Tese (Doutorado em História), Faculdade de Filosofia, Letras e Ciências Humanas da Universidade de São Paulo (USP). São Paulo. 2008.

LESSER, Jeffrey. O Brasil e a questão judaica: imigração, diplomacia e preconceito. Rio de Janeiro: Imago, 1995.

MAIO, Marcos Chor. Qual antissemitismo? Relativizando a questão judaica no Brasil dos anos 30. In Dulce Pandolfi. Repensando o Estado Novo. Rio de Janeiro: FGV, 1999.

MENDES, José Sacchetta Ramos. Laços de Sangue, Privilégios e Intolerância à Imigração Portuguesa no Brasil (1822-1945). Coleção Portugueses no Mundo. Porto: Fronteira do Caos; CEPESE, 2010.

. O sistema de cotas nas Constituições de 1934 e o ideal de integração

étnica dos estrangeiros no Brasil. In José Jobson Arruda, Vera Lucia Amaral Ferlini, Maria Izilda Matos, Fernando de Sousa. De colonos a Imigrantes, I(e)migração portuguesa para o Brasil. São Paulo: Alameda, 2013.

MUNIZ, João Carlos. Apresentação. Revista de Imigração e Colonização. Rio de Janeiro. Ano I. n.1. 1940.

\section{Filstortorias}


NEIVA, Arthur Hehl. Estudos sobre a imigração Semita no Brasil. Revista de Imigração e Colonização. Rio de Janeiro. Ano V, n.2, 1944.

Getúlio Vargas e o problema da imigração e da colonização. Revista de Imigração e Colonização. Rio de Janeiro. Ano III, n.1, 1942.

NEVES, Frederico de Castro. Getúlio e a seca: políticas emergenciais na era Vargas. Revista Brasileira de História. São Paulo, v. 21, n. 40, 2001.

OLIVERA, Antônio Xavier de. Nova Contribuição ao Estatuto do problema Imigratório no Brasil. Revista de Imigração e Colonização. Rio de Janeiro. Ano V, n.4, 1944.

PERES, Elena Pájaro. "Proverbial Hospitalidade? A Revista de Imigração e Colonização e o discurso oficial sobre o imigrante (1945-1955)”. Revista Acervo. Rio de Janeiro, v. 10, n. 2, 1997.

REVORÊDO, Júlio de. Imigração. São Paulo: Empresa Gráfica Revista dos Tribunais. 1934.

SEYFERTH, Giralda. Os imigrantes e a campanha de nacionalização do Estado Novo. In Dulce Pandolfi. Repensando o Estado Novo. Rio de Janeiro: FGV, 1999.

SILVA, Érica Sarmineto da. A "não democracia” dos excluídos alguns pontos da política imigratória brasileira. LOGOS 27: Mídia e democracia. Ano 14, $2^{\circ}$ semestre 2007. 